\title{
Introduction: Menstruation as Rationale
}

\author{
Breanne Fabs
}

Menstruation has been used as an excuse in many contexts. There is much legal and historical precedent linking menstruation to the category woman, and the limited political rights offered to persons therein. This section looks, in part, at the ways that menstruation has been used as a rationale to purposely curtail women's political rights, access to legal processes, and/ or benefits of citizenship. The way that stories of exclusion are built, often through norms of constructing menstruation as disabling and as a liability, constitute the core of this section.

Politicians have invoked the menstrual rationale to make clear that women do not belong: G. Gordon Liddy on Sonia Sotomayor and her confirmation to the US Supreme Court; Newt Gingrich on women having "biological problems" being out on the battle field for thirty days; Donald Trump on debate moderator Megyn Kelly who had "blood coming out of her whatever." They all used menstruation to signal woman, and in particular, woman "out of place." This rationale also appears in court cases, such as the use of PMS as a legal defense, to rules about when women can and cannot participate in sports or participate or enter religious sites. Further, the ways that these stories getting stacked upon one another-the military feeding stories of exclusion to the media, schools feeding stories of exclusion to the institutional practices of the family-mean that pushing women into ever-more-narrow boxes has resulted in a diminishing of the menstrual experience.

Conversely, the rationale can also be used as a source of bodily assertion and inspiration to challenge the menstrual status quo. No one accomplished this with more wit and incisiveness than Gloria Steinem with her short satirical essay, "If Men Could Menstruate," which succinctly underscored meanings of menstruation by turning the tables on men, revealing the ironic cultural constructions argued as innate. Steinem's essay was both 
funny and furious, drawing upon both humor and a serious consideration of the risks of leaving the status quo intact. This approach includes the rapidly growing constellation of activist efforts that seek to wrest menstruation from, for example, the Femcare industry. These alternative discourses empower menstruators themselves to redefine the meaning of menstruation and its embodiment at political, spiritual, and social levels.

Chapters in this section, then, explore the menstrual rationale, as well as critiques of the uses and abuses of the persistent and global menstrual taboo to market an ever expanding array of menstrual care products, from tampons to pharmaceuticals such as cycle-stopping contraceptives, a.k.a., menstrual suppressants and hormone therapies for menopausal women. These chapters include theoretical essays, cultural studies analyses, substantive literature reviews, historical reviews, and personal reflections, all of which reveal the breadth of ways in which scholars and writers have conceptualized the menstrual rationale.

We begin with Josefin Persdotter when she evokes the figure of the "menstrual monster" to challenge and reorient ideas about menstrunormativity, particularly as she welcomes and celebrates the idea of the "monstrous" menstruator as a figure that smashes rationales for excluding women from social and political rights. To imagine menstrual "normativity" is, in a sense, to also conceptualize menstrual non-normativity, a concept with many hazardous implications for the diverse group of people who menstruate.

In this light, Ela Przybylo and Breanne Fahs show the insidious workings of menstrual stories through menstrual product advertisements, revealing the ways that corporations and capitalism draw upon "empowerment" rhetoric only to further stigmatize menstruators. By foregrounding happy, able-bodied, celebratory periods, menstrual product advertisements ultimately shape narratives that excludes menstrual crankiness and any body/ shape/size outside of the narrow "ideal." In essence, only certain forms of emotional and affective experience are welcomed and allowed within the corporate framing of menstruation. Connected to this embrace of menstrual crankiness, Maureen McHugh argues for the importance of critically examining "menstrual moaning," or the ways that women talk negatively about their periods. Linking menstrual moaning to fat talk, McHugh asks whether we should embrace menstrual moaning or move toward more positive visions of menstrual experiences. In both chapters, notions of how women are excluded from disliking or liking their periods, and how emotional experiences of menstruation are regulated closely and intensely, constitute a core question in these chapters.

We next consider from a psychological perspective the much-understudied framework of men and boy's attitudes about menstruation, particularly as they internalize ideas of menstruation as a rationale for sexist notions of women's "out of control" moods, dismissal of women's pain or discomfort, and silence around the menstrual experience. The limited ways that boys learn about menstruation-or are expected to know about it-shows both 
how boys and men are not framed as invested in women's bodies and health, but also how menstruation becomes a key criteria for how men learn to discount and insult women.

We then move to a more global focus on the menstrual rationale, starting with Milena Bacalja Perianes and Dalitso Ndaferankhande reflecting on menarche rituals in Malawai and how starting to menstruate situates girls in a double bind: they both become women and thereby gain power and status, but they also face narrow social scripts about how they can behave and what menstruation means. In the following chapter, Sheryl Mendlinger offers a personal reflection essay in which she considers the span of her 30-year career studying menstrual health alongside ideas about cultural differences between Israel and the United States. Drawing on her work interviewing 48 mother-daughter dyads from Israel, including many immigrant women, she encourages a better understanding of the ways that knowledge of menstruation is acquired and how menarche stories contain a wide range of emotional experiences that speak not only to women and their bodies but also to the movement of immigration itself. This powerful back and forth-between empowerment and constraint, newfound freedoms and entrenched traditions-represents broader stories about menstruation as rationale.

This section concludes with a transnational engagements chapter that looks at menstrual health education throughout the world, detailing the wide range of approaches to studying, managing, and disseminating menstrual knowledge that is situated in diverse cultural contexts. This chapter features people speaking together from different cultural and geographical backgrounds to better understand how to teach people about menstruation. Ultimately, this transnational engagements chapter shows the power of an "all hands on deck" mentality to menstrual inclusion, as we learn about the fusion in menstrual health education between public and private sector, formalized non-profits and scrappy activism, medical doctors and local teachers, and fancy technology and folk wisdom. It is a reminder about how to best topple the barriers that women (and all menstruators) face when menstruation is used as a rationale for exclusion: go to the root of the problem and work collaboratively and in the spirit of social justice for all. 
Open Access This chapter is licensed under the terms of the Creative Commons Attribution 4.0 International License (http://creativecommons.org/licenses/ by/4.0/), which permits use, sharing, adaptation, distribution and reproduction in any medium or format, as long as you give appropriate credit to the original author(s) and the source, provide a link to the Creative Commons license and indicate if changes were made.

The images or other third party material in this chapter are included in the chapter's Creative Commons license, unless indicated otherwise in a credit line to the material. If material is not included in the chapter's Creative Commons license and your intended use is not permitted by statutory regulation or exceeds the permitted use, you will need to obtain permission directly from the copyright holder. 